\title{
Co-existence of severe insulin resistance and hyperinsulinaemia in pre-adolescent obese children
}

\author{
S. Caprio ${ }^{1}$, M. Bronson ${ }^{1}$, R .S. Sherwin ${ }^{2}$, F. R ife ${ }^{2}$, W.V. Tamborlane ${ }^{3}$ \\ ${ }^{1} \mathrm{D}$ epartment of Pediatrics, Y ale U niversity School of M edicine, $\mathrm{N}$ ew H aven, Connecticut, U SA \\ ${ }^{2} \mathrm{D}$ epartment of Internal M edicine, Y ale U niversity School of M edicine, $\mathrm{N} \mathrm{ew} \mathrm{H}$ aven, C onnecticut, U SA \\ ${ }^{3}$ Y ale Children's G eneral Clinical R esearch Center, Y ale U niversity School of M edicine, N ew H aven, Connecticut,U SA
}

Summary To determine the time course of changes in insulin action and secretion that occur early during the development of obesity, we studied children before the onset of puberty. The reason for choosing the prepubertal stage of development is that it is metabolically characterized by both a high sensitivity to insulin and low glucose stimulated insulin responses. Fifteen obese preadolescents ( 8 male/7 female, age $10 \pm 0.4$ years, body mass index (B M ) $31 \pm 1.2 \mathrm{~kg} / \mathrm{m}^{2}$ Tanner Stage I) with a duration of obesity of less than 5 years and 10 non-obese preadolescents $(6 \mathrm{male} / 4$ female, age $10 \pm 0.4$ years, BMI $18 \pm 0.9 \mathrm{~kg} / \mathrm{m}^{2}$ ) matched for gender were studied. In a cross-sectional analysis, we compared responses in obese preadolescents, with those in obese adolescents and obese adults with a longer duration of obesity. The euglycaemic hyperinsulinaemic clamp with $1-{ }^{13} \mathrm{C}$-glucose ( $\mathrm{H}$ ot $\mathrm{G}$ inf) and indirect calorimetry were used to quantitate insulin action and the hyperglycaemic clamp used to assess beta-cell function. Insulin-stimulated glucose uptake measured at two physiological levels of hyperinsulinaemia ( 180 and 480 pmol) was reduced by 20 and $45 \%$ in all three groups of obese compared to non-obese subjects $(p<0.01)$. D efects in oxidative and non-oxidative glucose metabolism were observed in all three groups of obese subjects at the higher insulin infusion rate. The ability of insulin to inhibit lipid oxidation was impaired in all three obese groups at both levels of hyperinsulinaemia. Increases in basal and glucose-stimulated insulin levels during the hyperglycaemic clamp mirrored the reductions in glucose uptake during the insulin clamp in all obese groups. These results indicate that insulin resistance and hyperinsulinaemia co-exist in preadolescent children with moderate to severe obesity. [D iabetologia (1996) 39: 1489-1497]

Keywords Obesity, preadolescents, hyperinsulinaemia, insulin resistance.
Insulin resistance is a prominent feature of both human and animal obesity [1-3]. In response to this inslin insensitivity, the pancreatic beta cell augments its insulin secretion and the resultant hyperinsulinaemia maintains normal glucose homeostasis [4]. Hence, in human obesity hyperinsulinaemia is generally

R eceived: 23 M arch 1996 and in revised form: 16 J uly 1996

Corresponding author: Dr. S. Caprio, D epartment of Pediatrics, 333 Cedar Street, Yale U niversity School of Medicine, $\mathrm{N}$ ew $\mathrm{H}$ aven, CT 06520, USA

A bbreviations: NEFA, N on-esterified fatty acid; H G P, hepatic glucose production; $R_{a}$, rate of glucose appearance; $R_{d}$, rate of glucose disappearance. considered secondary to the defects in insulin action [5]. On the other hand, hyperinsulinaemia, which is used as a biochemical marker of insulin resistance has itself been implicated in the development and maintenance of excess adiposity [6-8]. R ecently, Le Stunff and Bougnères [9] elegantly demonstrated a dysregulation of beta-cell function in juvenile-onset obesity. This abnormal pattern of insulin response to meals was followed by the development of hyperinsulinaemia and insulin resistance. The results of their study, however, do not agree with the conclusion that insulin sensitivity is not compromised early in the natural course of obesity. It is quite clear from the meal study that both groups of obese children had significantly high post-meal plasma glucose 
Table 1. Clincial characteristics

\begin{tabular}{|c|c|c|c|c|c|c|}
\hline \multirow[t]{2}{*}{$n$} & \multicolumn{2}{|c|}{ Pre-adolescents } & \multicolumn{2}{|l|}{ A dolescents } & \multicolumn{2}{|l|}{ A dults } \\
\hline & $\begin{array}{l}\text { Non-obese } \\
10\end{array}$ & $\begin{array}{l}\text { O bese } \\
15\end{array}$ & $\begin{array}{l}\text { Non-obese } \\
16\end{array}$ & $\begin{array}{l}\text { O bese } \\
18\end{array}$ & $\begin{array}{l}\text { Non-obese } \\
18\end{array}$ & $\begin{array}{l}\text { O bese } \\
8\end{array}$ \\
\hline A ge (years) & $10.6 \pm 0.4$ & $10 \pm 0.4$ & $13.6 \pm 0.2$ & $13 \pm 0.4$ & $24 \pm 0.5$ & $27 \pm 3.4$ \\
\hline Height (cm) & $142 \pm 3$ & $145 \pm 3$ & $160 \pm 2$ & $160 \pm 2$ & $166 \pm 2$ & $169 \pm 3$ \\
\hline Weight (kg) & $37 \pm 3$ & $67 \pm 4^{a}$ & $56 \pm 2$ & $81 \pm 5^{a}$ & $59 \pm 2$ & $87 \pm 4$ \\
\hline Body mass index $\left(\mathrm{kg} / \mathrm{m}^{2}\right)$ & $18 \pm 0.9$ & $31.2 \pm 1.2^{\mathrm{a}}$ & $22.2 \pm 0.4$ & $30.5 \pm 1.1^{a}$ & $21 \pm 0.5$ & $34 \pm 1.6^{a}$ \\
\hline $\begin{array}{l}\text { Insulin-like growth factor-1 } \\
\text { (ng/ml) }\end{array}$ & $207 \pm 24$ & $256 \pm 24$ & $491 \pm 39^{a}$ & $357 \pm 38$ & $275 \pm 19$ & $246 \pm 34$ \\
\hline $\begin{array}{l}\text { Fasting plasma } \\
\text { glucose ( } \mathrm{mmol} / \mathrm{l})\end{array}$ & $4.7 \pm 0.1$ & $4.9 \pm 0.17$ & $5.0 \pm 0.1$ & $4.6 \pm 0.2$ & $5.2 \pm 0.1$ & $5.0 \pm 0.09$ \\
\hline $\begin{array}{l}\text { Duration of } \\
\text { obesity (years) }\end{array}$ & - & $<5$ & - & $>5$ & - & $>10$ \\
\hline
\end{tabular}

$\mathrm{D}$ ata are mean $\pm \mathrm{SE} M$

a $p<0.01$ vs non-obese subjects

levels ( $5.65 \pm 0.11 \mathrm{mmol} / \mathrm{l})$ vs normal children ( $4.34 \pm$ $0.09 \mathrm{mmol} / \mathrm{l})(p<0.005)$. These elevated plasma glucose levels, despite hyperinsulinaemia, are indicative of an underlying defect in insulin action. Furthermore, a clear distinction of prepubertal and pubertal children is important in studying both insulin action and secretion in view of the physiological changes that are known to occur. R elatively little attention has been paid to the metabolic consequences of obesity in preadolescents, even though such studies might provide important insights into the natural history of the disease. Prepuberty is the ideal developmental stage for studying these issues, because non-obese preadolescents are metabolically characterized by both a high sensitivity to insulin [10] and low glucose-stimulated insulin responses [11]. M oreover, by studying prepubertal children it is possible to eliminate the confounding hormonal and metabolic effects of puberty per se on insulin action and secretion [12].

In this study, we have employed the euglycaemic hyperinsulinaemic and hyperglycaemic clamp techniques in combination with ${ }^{13} \mathrm{C}$-glucose and indirect calorimetry in a group of prepubertal obese children to determine the time course of changes in insulin action and secretion during the earliest stage of obesity. In a cross-sectional analysis, we compared responses in preadolescents with a relatively short duration of obesity with responses in obese adolescents and young adults and in age-matched non-obese control subjects. Thus, we were able to assess the impact of obesity on the developmental changes in insulin action and insulin secretion that are normally observed in childhood.
Subjects and methods

Study population. Three groups of obese subjects were studied: a) 15 obese preadolescent ( 8 male/7 female) children, age range $7-11$ years and a $B$ M I of $31.2 \pm 1.2 \mathrm{~kg} / \mathrm{m}^{2} ; \%$ ideal body weight $177 \pm 7$, ranging from 127 to $215 \%$; b) 18 obese adolescents ( 6 male/ 12 female), age range $11-16$ years and a B M I of $30.5 \pm 1.1 ; \%$ ideal body weight $159 \pm 5$ ranging from 130 to $206 \%$; and 8 obese adult females, age range $18-40$ years and a $\mathrm{BMI}$ of $34 \pm 1.6 ; \%$ ideal body weight $163 \pm 7$, ranging from 130 to $200 \%$. Ten non-obese preadolescents and 16 non-obese adolescents matched for gender, age and pubertal stage of development served as the control groups for the obese children, whereas 18 non-obese adults were the group of comparison for the adult obese subjects. Their clinical and biochemical characteristics are shown in Table 1 . The obese children were recruited from the Yale Pediatric Weight Management Clinic and the obese adults from the $Y$ ale Women's H ealth program. A detailed medical and nutritional history was obtained for each subject. During the physical examination height and weight were measured while the subjects were fasting and wearing only their undergarments. BMI or Quetelet index was then calculated as weight in $\mathrm{kg}$ over height $\left(\mathrm{m}^{2}\right)$ and this was used as indirect measure of adiposity. O besity in adults was defined by B M I greater than 27 . A II obese children had a BMI greater than 95th percentile specific for age and sex (based on percentile curves for Caucasian girls and boys computed from the first $\mathrm{N}$ ational $\mathrm{H}$ ealth and Nutrition $\mathrm{E}$ xamination Survey 1971 to 1974) [13]. None of the children had any chronic diseases. A Il children were in good health, taking no medications and had never attempted to lose weight. $D$ ata on the onset of excessive weight gain was obtained from growth curve charts provided by the pediatrician. In all young obese adults the onset of excess adiposity started during childhood. Tanner stage of pubic hair, breast or genital development was assessed prior to participating in the clamp study by physical 
examination. A II females were studied in the follicular phase. Plasma samples for measurement of estradiol, testosterone and insulin-like growth factor 1 were also used as biochemical markers of pubertal development. Prepubertal boys had testes volume of 2-3 ml, no pubic hair and plasma testosterone less than $0.50 \mathrm{ng} / \mathrm{ml}$. Prepubertal girls had no pubic hair or breast development and levels of plasma estradiol of less than $15 \mathrm{pg} /$ $\mathrm{ml}$. Tanner stage development in the adolescent children ranged between Stage II and IV. Plasma insulin-like growth factor 1 levels were greater in non-obese than obese preadolescents. Subtle differences in sexual maturation and nutritional status may account for this difference. $D$ ata on the obese adolescent girls, on 9 non-obese girls and on 12 young lean adult women have been used previously to describe the relationships between insulin action and secretion and intra-abdominal fat depot in obese adolescent girls [14].

A II subjects were normally active and none was participating in an organized physical training programme. Smokers and alcohol drinkers were excluded from the study. Subjects consumed an isocaloric diet, containing approximately $250 \mathrm{~g}$ of carbohydrate per day for 7 days before study, as confirmed by dietary history and consistency of body weight. The nature and purpose of the study were carefully explained to both parents and to the children before obtaining written voluntary consent to participate. The study protocols were approved by the Human Investigation Committee of the Yale U niversity School of Medicine.

M etabolic studies. On the day of the study, subjects were admitted at 08.00 hours to the $Y$ ale $G$ eneral $C$ linical R esearch $C$ enter (child or adult units). A II studies were performed after an overnight fast of 10-12 h, with the subject lying supine in a quiet room. Two i.v. catheters were inserted before the clamp studies: one in an antecubital vein for administration of test substances and the other in a vein of the hand or distal forearm of the contralateral arm for blood sampling. The hand chosen for blood sampling was placed in a heated box (approximately $65^{\circ} \mathrm{C}$ ) to facilitate blood sampling and to arterialize blood. The following studies were performed: 1) a sequential two-step euglycaemic insulin clamp in combination with the infusion of ${ }^{13} \mathrm{C}$-glucose and indirect calorimetry, and 2) a $+6.9 \mathrm{mmol} / /$ hyperglycaemic clamp. The two studies were performed in random order at 2month intervals. Six preadolescent and 10 adolescent obese subjects performed both studies.

Q uantification of insulin sensitivity. We used a two-step euglycaemic hyperinsulinaemic clamp to assess total body insulin sensitivity. Insulin was administered as a prime continuous infusion at rates of 8 and $40 \mathrm{mU} \cdot \mathrm{m}^{-2} \cdot \mathrm{min}^{-1}$ of body surface area. Each step lasted $120 \mathrm{~min}$. Hepatic glucose production was quantitated by infusing $1{ }^{13} \mathrm{C}$-glucose as a prime continuous infusion starting 120 min before the beginning of the sequential insulin clamp. Plasma enrichment of $1^{1-{ }^{13}} \mathrm{C}$-glucose was kept constant at basal value throughout the clamp by adding a sufficient amount of $1^{1-13} \mathrm{C}$-glucose to the $20 \%$ glucose infusate (H ot G INF) [15]. U sing the H ot G INF approach, the calculated rate of tracer appearance closely approximates the glucose infusion rate. D uring the last $30 \mathrm{~min}$ of the basal and insulin infusion periods arterialized samples were collected at 10 -min intervals for determination of $1-{ }^{13} \mathrm{C}$-glucose enrichment, hormones and substrates. E stimation of net rates of carbohydrate and lipid oxidation were obtained by employing indirect calorimetry at baseline and during the last 30 min of each insulin step. D uring similar periods urine was collected and analysed for nitrogen excretion, which was used to evaluate protein oxidation. The euglycaemic hyperinsulinaemic clamp study was performed in 8 obese and 6 non-obese preadolescents, in 13 obese and 13 non-obese adolescents and in 6 obese and 12 non-obese young adults.

Pancreatic $\beta$-cell function assessment. The hyperglycaemic clamp technique was used to assess the secretory response of pancreatic beta cells to a standard increase in plasma glucose in obese and non-obese children [16]. A fter the collection of three baseline samples, glucose was acutely raised by $7 \mathrm{mmol} / \mathrm{l}$ with a priming infusion of $20 \%$ glucose. Subsequently, plasma glucose (measured at 5-min intervals) was held constant at this hyperglycaemic level for 120 min by appropriate adjustment of a variable-rate $20 \%$ glucose infusion. B lood samples were also obtained at 2, 4, 6, 8, and $10 \mathrm{~min}$ and every $10 \mathrm{~min}$ thereafter for $120 \mathrm{~min}$, for measurements of plasma insulin and $\mathrm{C}$-peptide concentrations. U rine was collected at the beginning and end of the procedure for determination of glucose content. The hyperglycaemic clamp study was performed in 11 obese preadolescents, in 7 non-obese preadolescents, in 18 obese adolescents, 10 non-obese adolescents in 6 obese adults and 6 non-obese adults.

D eterminations and calculations. Plasma and urine glucose levels were measured by the glucose oxidase method with a B eckman glucose analyser (Beckman Instruments, B rea, Calif., U SA ). Plasma insulin and C-peptide were measured by a double-antibody radioimmunoassay. Plasma non-esterified fatty acids (NEFA) was assayed by a colourimetric method [17] and urinary nitrogen by the Kjeldahl procedure [18]. Total $\mathrm{H} \mathrm{bA}_{1}$ was measured chromatographically with a microcolumn (I solab, A kron, O hio, U SA ). Plasma dehydroepiandrosterone sulphate was measured by radioimmunoassay. The $\left[{ }^{13} \mathrm{C}\right]$ enrichment of plasma glucose was determined by gas chromatograph-mass spectrometry of the penta acetate derivatives of glucose after deproteinization and dionization as previously described [19]. G as chromatography-mass spectrometry analysis was performed with a H ewlett-Packard 5890 gas chromatograph interfaced with a H ewlett-Packard 5971A mass selective detector operating in the chemical impact mode (70 eV).

Glucose metabolism and hepatic glucose production (HGP). D uring the last $30 \mathrm{~min}$ of the equilibration period and during the last 30 min of each step of the insulin clamp, a steady-state plasma enrichment of $\left[1^{-13} \mathrm{C}\right]$-glucose was achieved in all three groups. Therefore, in both the basal and insulin-stimulated states, the rate of glucose appearance $\left(R_{a}\right)$ equals the rate of total glucose disposal. Thus, glucose $R_{a}$ (rate of appearance) was calculated by the following formula:

$\mathrm{R}_{\mathrm{a}}=\mathrm{F} / \mathrm{E} 1 \mathrm{p}$

where $\mathrm{F}$ is the $\left[1-{ }^{13} \mathrm{C}\right]$-glucose infusion rate; $\mathrm{E} 1 \mathrm{p}$ is the $\left[1-{ }^{13} \mathrm{C}\right]$ glucose enrichment in plasma at isotopic plateau (atom\% excess) 19]. In the postabsorptive state, the only source of glucose entry into the body is the liver. Therefore, basal $R_{a}$ equals the rate of basal HG P. D uring the insulin infusion, $H G$ P was computed as the difference between isotopically determined $R_{a}$ of glucose and the exogenous glucose infusion rate. Total body glucose disposal $\left(R_{d}\right)$ during the insulin clamp was calculated by adding the rate of residual $\mathrm{H} \mathrm{G} P$ to the rate of exogenous glucose infusion corrected for changes in the glucose pool. R espiratory gas exchange rates were measured by a computerized open circuit indirect calorimetry (D eltatrac, Sensor M edics, $\mathrm{H}$ elsinki, Finland) with a ventilated hood system. Oxidation rates for carbohydrate, fat and protein before and during the clamp procedure were calculated from the measured $\mathrm{O}_{2}$ consumption, $\mathrm{CO}_{2}$ production and urinary nitrogen excretion, as previously described [20]. G lucose uptake and oxidation rates 
Table 2. B asal and steady-state plasma insulin levels (pmol) in the obese and non-obese subjects during the euglycaemic clamp study

\begin{tabular}{|c|c|c|c|c|c|c|}
\hline \multirow[t]{2}{*}{$n$} & \multicolumn{2}{|c|}{ Pre-adolescents } & \multicolumn{2}{|l|}{ A dolescents } & \multicolumn{2}{|l|}{ A dults } \\
\hline & $\begin{array}{l}\text { Non-obese } \\
6\end{array}$ & $\begin{array}{l}\text { O bese } \\
8\end{array}$ & $\begin{array}{l}\text { Non-obese } \\
13\end{array}$ & $\begin{array}{l}\text { O bese } \\
13\end{array}$ & $\begin{array}{l}\text { Non-obese } \\
12\end{array}$ & $\begin{array}{l}\text { O bese } \\
6\end{array}$ \\
\hline $\begin{array}{l}\text { Basal } \\
8 \mathrm{mU} \cdot \mathrm{m}^{-2} \cdot \mathrm{min}^{-1} \\
40 \mathrm{mU} \cdot \mathrm{m}^{-2} \cdot \mathrm{min}^{-1}\end{array}$ & $\begin{array}{c}30 \pm 6 \\
108 \pm 18 \\
336 \pm 36\end{array}$ & $\begin{array}{r}96 \pm 18^{a} \\
186 \pm 24^{a} \\
504 \pm 36^{a}\end{array}$ & $\begin{array}{c}54 \pm 6 \\
174 \pm 36 \\
384 \pm 43\end{array}$ & $\begin{array}{c}84 \pm 16^{a} \\
168 \pm 30 \\
480 \pm 36^{a}\end{array}$ & $\begin{array}{c}30 \pm 5 \\
90 \pm 6 \\
300 \pm 12\end{array}$ & $\begin{array}{r}84 \pm 16^{a} \\
168 \pm 30 \\
480 \pm 36^{a}\end{array}$ \\
\hline
\end{tabular}

Table 3. E ffect of insulin on endogenous glucose production in non-obese and obese preadolescents, adolescents and adults

\begin{tabular}{|c|c|c|c|c|c|c|}
\hline \multirow[t]{2}{*}{$\overline{\mathrm{mU} \cdot \mathrm{m}^{2} \cdot \mathrm{min}^{-1}}$} & \multicolumn{2}{|c|}{ Pre-adolescents } & \multicolumn{2}{|c|}{ A dolescents } & \multicolumn{2}{|l|}{ A dults } \\
\hline & Non-obese & O bese & Non-obese & 0 bese & Non-obese & $O$ bese \\
\hline $\begin{array}{c}\text { Basal } \\
8 \\
40\end{array}$ & $\begin{array}{c}103 \pm 5 \\
21 \pm 4 \\
8 \pm 10\end{array}$ & $\begin{array}{c}118 \pm 9 \\
16 \pm 10 \\
12 \pm 18\end{array}$ & $\begin{array}{r}113 \pm 4 \\
19 \pm 4 \\
10 \pm 1\end{array}$ & $\begin{array}{c}128 \pm 10 \\
24 \pm 3 \\
11 \pm 4\end{array}$ & $\begin{array}{l}89 \pm 2 \\
16 \pm 3 \\
16 \pm 8\end{array}$ & $\begin{array}{r}100 \pm 7 \\
20 \pm 5 \\
10 \pm 5\end{array}$ \\
\hline
\end{tabular}

D ata are mean \pm SE M

are adjusted per surface area determined by the Dubois formula.

H yperglycaemic clamp. D uring the hyperglycemic clamp procedure the plasma insulin response is biphasic; responses in the first phase $(0-10 \mathrm{~min})$ and late phase $(10-120 \mathrm{~min})$ were calculated as the mean hormone concentration during the respective time periods [16].

Statistical analysis. All values are presented as mean \pm SE M . Statistical analyses were performed with a two-way analysis of variance to compare the responses of the different groups over time (PROPHET statistical package, NIH's stats software). Single within and between group comparisons were analysed with the two-tailed paired or unpaired Student's t-test.

\section{Results}

Total body glucose disposal. B asal and steady-state plasma insulin levels during the euglycaemic clamp in the obese and non-obese subjects are reported in Table 2. A s can be seen in all three obese patient groups, fasting plasma insulin levels were identical. During the low and high insulin dose the steady-state plasma insulin concentration achieved was similar in all obese groups. B oth basal and steady-state plasma insulin levels were significantly higher in obese patient groups compared to their respective non-obese control groups $(p<0.02)$. I $n$ the non-obese subjects, fasting insulin levelswerehigher in the adolescents compared to both non-obese preadolescents and young adults, as previously observed [11]. Steady-state plasma insulin levels were also higher in the non-obese adolescents compared to the two other non-obese groups. Plasma glucose concentrations were maintained at basal levels (coefficients of variation $<5 \%$ ) during all studies.

Basal hepatic glucose production rates were slightly, but not significantly, higher in obese pre-adolescents $\left(118 \pm 9 \mathrm{mg} \cdot \mathrm{m}^{-2} \cdot \mathrm{min}^{-1}\right)$, obese adolescents $\left(128 \pm 10 \mathrm{mg} \cdot \mathrm{m}^{-2} \cdot \mathrm{min}^{-1}\right)$ and obese adults $\left(100 \pm 7 \mathrm{mg} \cdot \mathrm{m}^{-2} \cdot \mathrm{min}^{-1}\right)$ compared to their respective control groups $\left(103 \pm 5 \mathrm{mg} \cdot \mathrm{m}^{-2} \cdot \mathrm{min}^{-1}\right.$ preadolescents, $113 \pm 4 \mathrm{mg} \cdot \mathrm{m}^{-2} \cdot \mathrm{min}^{-1}$ adolescents and $89 \pm$ $2 \mathrm{mg} \cdot \mathrm{m}^{-2} \cdot \mathrm{min}^{-1}$ adults $\mathrm{p}=\mathrm{NS}$ ). Changes in hepatic glucose production during both low and high insulin infusions were similar in obese and non-obese groups, as shown in Table 3. H owever, it should be noted that this occurred in the obese subjects at greater plasma insulin levels. The effect of insulin on whole body glucose disposal in obese preadolescents, adolescents and adults is illustrated in Figure 1. In the preadolescent group, basal glucose uptake was similar in both obese and non-obese children. During the low-dose insulin clamp, while glucose uptake increased by $20 \%(p<0.05)$ in the non-obese children, it remained unchanged in the obese children. A greater difference between the two groups became apparent during the higher-dose insulin infusion, where glucose disposal rates in the obese preadolescents were $45 \%$ lower than those of non-obese preadolescents ( $205 \pm 0$ vs $\left.375 \pm 35 \mathrm{mg} \cdot \mathrm{m}^{-2} \cdot \mathrm{min}^{-1}, \mathrm{p}<0.01\right)$. G lucose oxidation rates in the basal state and during the first step of the insulin infusion were not different between the two preadolescent groups. In contrast, during the higher insulin dose infusion, both the oxidative and non-oxidative glucose metabolism were significantly reduced compared to that of the non-obese preadolescent children. G lucose uptake was also reduced in obese adolescents compared to non-obese children (Fig. 1, center panel) during the high insulin infusion, but no change in glucose turnover or glucose oxidation was observed in either group of adolescents during the low-dose insulin infusion. A similar pattern of responses to insulin was observed in the obese adult subjects whose glucose disposal rates were significantly 

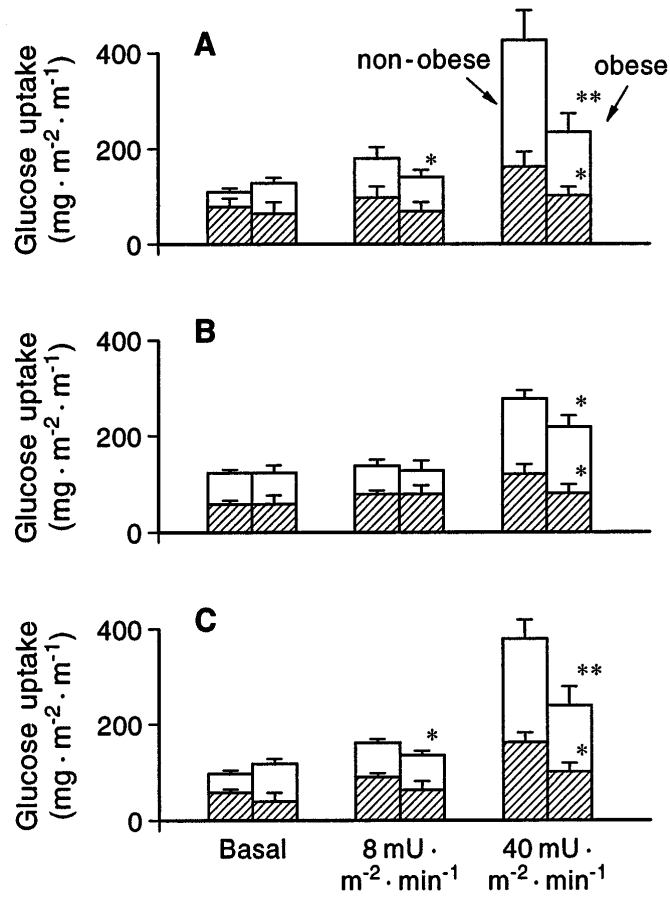

Fig. 1.A-C. Total body glucose disposal in obese and nonobese preadolescents $(\mathbf{A})$, in obese and non-obese adolescents (B) and obese and non-obese adults (C) during the 8 and $40 \mathrm{mU} \cdot \mathrm{m}^{-2} \cdot \mathrm{min}^{-1}$ euglycaemic clamp studies. Oxidative $\mathbb{R}$ and non-oxidative $\square$ glucose metabolism are shown. ${ }^{*} \mathrm{p}<0.05 ;{ }^{* *} \mathrm{p}<0.01$

lower than the non-obese young subjects during both steps of the insulin clamp study $(p<0.05, p<0.01)$.

Figure 2 compares the effect of obesity at three different developmental stages on the insulin dose-response curve. A II three groups of obese subjects had the same insulin dose response curve. Thus, the ability of insulin to promote in vivo glucose metabolism is compromised already in preadolescent obese children.

NEFA levels and fat oxidation. The effect of insulin on changes in plasma NEFA and fat oxidation rates

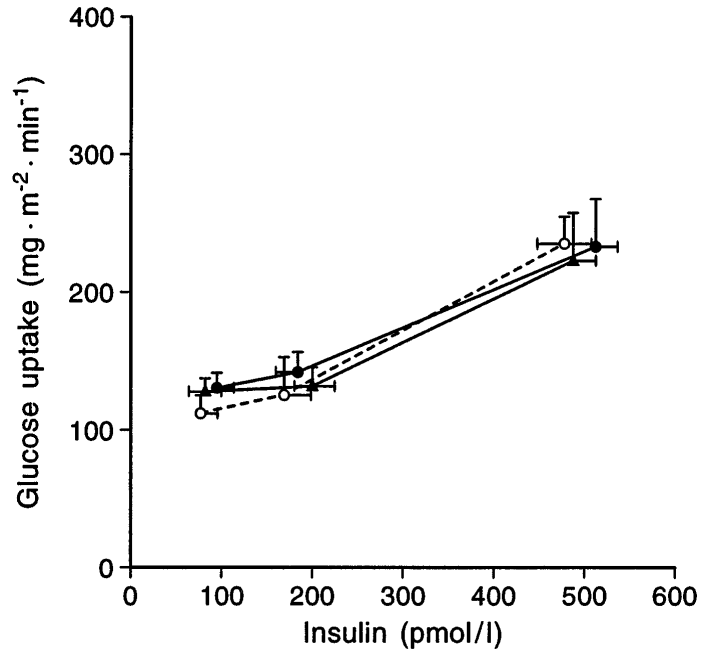

Fig. 2. E ffects of obesity on the insulin dose response curve in obese preadolescents $(\bullet)$, adolescents $(\boldsymbol{\Lambda})$ and adults (०)

during the insulin clamp study in obese and non-obese preadolescents, adolescents and young adults is illustrated in Table 4. In the preadolescent obese children both basal and (during the two insulin steps) plasma NEFA were not significantly different from those of the non-obese preadolescent children. In contrast, in the other obese groups the suppressive effect of insulin on plasma NEFA levels was significantly lower than that on the non-obese control subjects.

B asal fat oxidation rates were slightly greater in obese vs non-obese preadolescents and no change from baseline occurred in the obese preadolescents at any step of the clamp study (Table 4). The same lack of suppression of fat oxidation rates as of insulin was observed in the two other groups of obese subjects (Table 4), whereas the high-dose insulin infusion consistently lowered the rate of fat oxidation in all three groups of non-obese subjects $(p<0.05-0.02$ vs obese subjects).

Table 4. E ffect of insulin on changes in plasma NE FA levels and fat oxidation rates in obese and non-obese preadolescents, adolescents and adults

\begin{tabular}{|c|c|c|c|c|c|c|}
\hline & \multicolumn{2}{|c|}{ Preadolescents } & \multicolumn{2}{|c|}{ A dolescents } & \multicolumn{2}{|l|}{ A dults } \\
\hline & Non-obese & Obese & Non-obese & O bese & Non-obese & O bese \\
\hline $\begin{array}{l}\text { Plasma NE FA } \\
(\mu \mathrm{mol} / \mathrm{ll}) \\
\text { B asal }\end{array}$ & $994 \pm 80$ & $1031 \pm 77$ & $791 \pm 74$ & $681 \pm 50$ & $530 \pm 30$ & $700 \pm 90$ \\
\hline $\begin{array}{l}8 \mathrm{mU} \cdot \mathrm{m}^{-2} \cdot \mathrm{min}^{-1} \\
40 \mathrm{mU} \cdot \mathrm{m}^{-2} \cdot \mathrm{min}^{-1}\end{array}$ & $\begin{array}{l}405 \pm 66 \\
340 \pm 40\end{array}$ & $\begin{array}{l}480 \pm 28 \\
340 \pm 40\end{array}$ & $\begin{array}{l}240 \pm 30 \\
200 \pm 20\end{array}$ & $\begin{array}{l}352 \pm 40^{\mathrm{a}} \\
287 \pm 30^{\mathrm{a}}\end{array}$ & $\begin{array}{l}110 \pm 10 \\
110 \pm 20\end{array}$ & $\begin{array}{l}225 \pm 30^{a} \\
200 \pm 20^{a}\end{array}$ \\
\hline
\end{tabular}

$\mathrm{D}$ ata are mean $\pm \mathrm{SE} M$

a $p<0.02$ obese vs non-obese adolescents and adults 

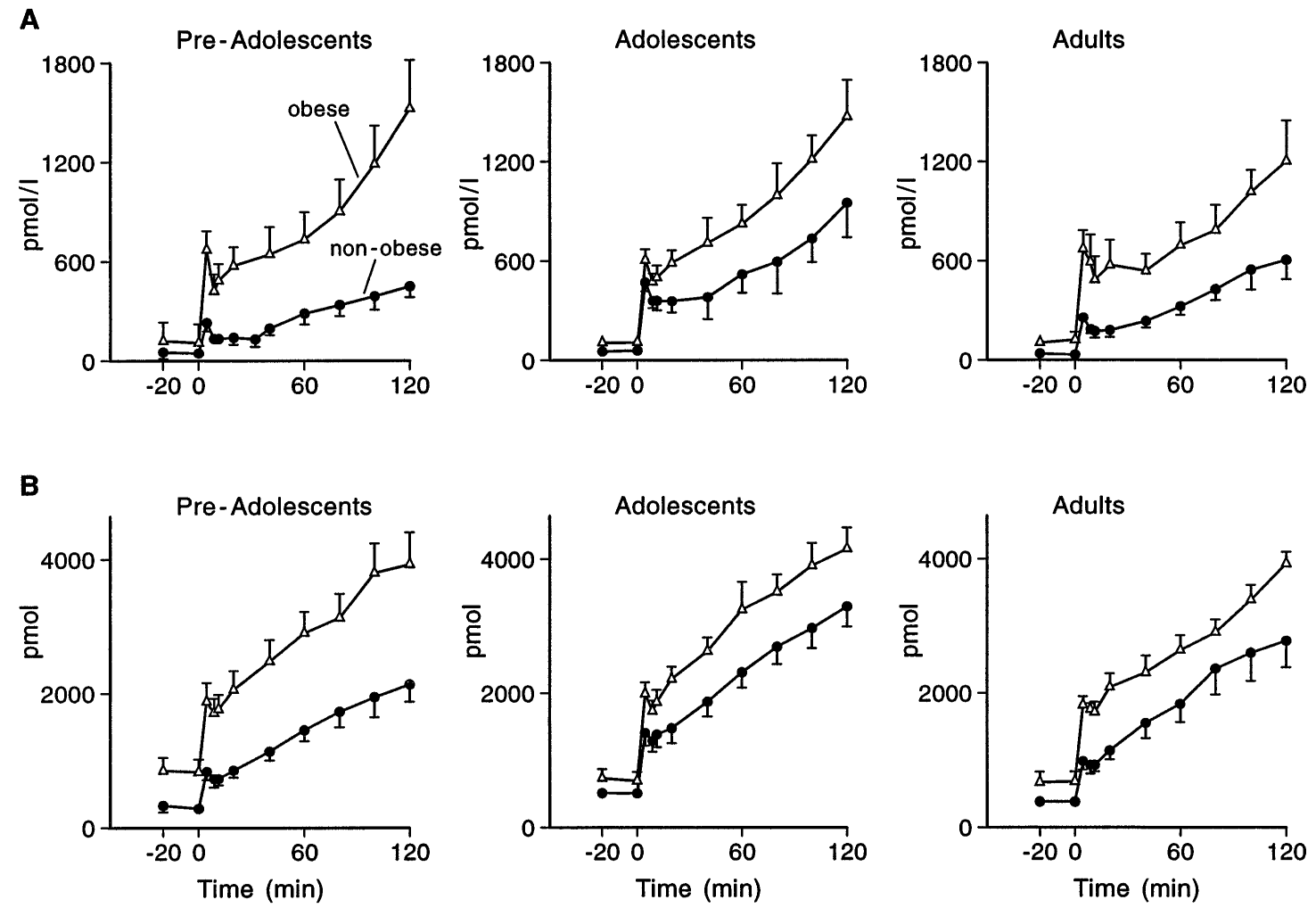

Fig. 3. A , B. Changes in plasma insulin (A) and C-peptide (B) levels during the hyperglycaemic clamp studies in obese and non-obese preadolescents, obese and non-obese adolescents and obese and non-obese adults

B eta-cell function. B aseline levels of plasma C-peptide as well as insulin were already greater in obese vs non-obese $(p<0.01)$ preadolescents (Fig. 3). D uring the hyperglycaemic clamp, a biphasic pattern of insulin responses occurred in both obese and non-obese preadolescents. However, the magnitude of the response was much greater in the obese vs non-obese preadolescent children (Fig. 3). The first (498 \pm 78 $\mathrm{pmol} / \mathrm{l})$ and late $(900 \pm 174 \mathrm{pmol} / \mathrm{l})$ phase insulin responses in the obese preadolescent were three- to five-fold greater than those in the non-obese preadolescents ( $144 \pm 30$ pmol; $282 \pm 48$ pmol, $p<0.001$ vs obese). Similarly, both first phase and late phase Cpeptide responses were higher in the obese than in non-obese preadolescent children. In the obese adolescents and adults insulin and C-peptide responses were also significantly greater than those in the nonobese control subjects.

\section{Discussion}

To determine the sequence of metabolic events that occur during the earliest stage of juvenile obesity, we studied preadolescent obese children. The hormonal and significant changes in body composition that occur during puberty favour the development of insulin resistance and compensatory hyperinsulinaemia $[12,21]$. Therefore, this developmental stage is not ideal for examining putative alterations in both insulin action and secretion in the development of obesity. In contrast, healthy, non-obese prepubertal children are exquisitely sensitive to insulin and have low glucose-stimulated insulin response [11]. O ur study indicates that insulin resistance and hyperinsulinaemia coexist in preadolescent children with a relatively short duration of excess adiposity. The degree of impairment in insulin action and hypersecretion of insulin in these young obese preadolescent children was the same as that observed in both adolescents and obese adults with a longer duration of the obese state. Hence, these data suggest that the impact of obesity on glucose metabolism is totally independent of the duration of obesity. It should be noted, however, that the degree of obesity in the preadolescent children varied from moderate to severe; it is therefore possible that puberty might worsen insulin sensitivity in children with a milder degree of obesity.

The primary neuroendocrine/metabolic defect(s) responsible for the development of obesity in both humans and animals remains unknown. Controversy still remains as to whether increased insulin secretion and the resultant hyperinsulinaemia is a primary aetiological factor or secondary to the establishment of obesity. A nimal models of obesity such as the genetically pre-obese Z ucker rats and rats with experimentally induced obesity by means of ventromedial hypothalamic lesions, display an initial increase in insulin 
secretion in response to glucose; subsequently, both basal and glucose-stimulated hyperinsulinaemia are present $[22,23]$. Insulin resistance develops secondarily and is characterized by impaired glucose metabolism as well as by defective suppression of lipolysis [24]. Chronic hyperinsulinaemia induced by exogenous infusion of insulin in man has been found to induce resistance in some $[8,25]$ but not all studies [26]. H owever, it should be noted that in most studies hypoglycaemia in response to the chronic insulin infusion was not carefully avoided. Therefore, it is conceivable that hypoglycaemic counter-regulatory responses contributed to some extent to the development of the insulin-resistant state in these experiments. More recently, in studies using transgenic mice over-expressing the human insulin gene, hyperinsulinaemia has been found to lead to insulin resistance [27]. M cG arry [28] has recently proposed an interesting working hypothesis to explain the development of insulin resistance. A ccording to this hypothesis, an unidentified central inherited defect (leptin resistance?) will lead to hyperinsulinaemia which, in turn, will cause increased hepatic lipogenesis and very low density lipoprotein (V LDL) synthesis. The excessive delivery of VLDL to muscle and adipose tissue causes deposition of triglycerides. Fat accumulation in muscle interferes with glucose storage and oxidation leading to insulin resistance which, in turn, will create a vicious cycle causing even greater insulin resistance. H owever, attractive as it is, this hypothesis, needs to be proven. Interestingly, A bbott and Foley [29] found higher plasma insul in levels and plasma glucose levels during an oral glucose load in lean prepubertal Pima Indian children compared with Caucasian children. M ore recently, 0 deley et al. [30] found high fasting insulin levels in 5-10-year-old Pima Indians to be predictive of teenage obesity.

In healthy normal subjects insulin secretion is closely linked to insulin sensitivity such that any change in insulin action is carefully balanced by an increased insulin production. Thus, insulin action and secretion interact upon each other. B ecause of this intricate partnership it may be difficult to determine whether an alteration in insulin action or secretion is primary or secondary. Thus, it is not surprising that the obese preadolescents in this study presented with increased basal insulin levels and markedly exaggerated insulin responses to intravenous glucose compared to the non-obese preadolescents. Likewise, basal C-peptide levels and plasma C-peptide response closely followed that of insulin, indicating true hypersecretion of insulin.

In contrast, Le Stunff and Bougnères [9] reported increased insulin responses to meals in a group of obese children, whose duration of obesity was less than 5 years, even though fasting insulin levels and insulin sensitivity did not differ from values in nonobese control subjects. In their study, however, during the meal test despite the marked hyperinsulinaemia observed in the obese group, post-meal plasma glucose remained significantly elevated compared to control subjects. This finding would indicate an already impaired insulin sensitivity together with hyperinsulinaemia. Several factors may explain the disparate findings between our study and those of Le Stunff and B ougnères [9]. First, the degree of obesity of the subjects studied by Le Stunff and Bougnères was less (body weight $60 \pm 5 \mathrm{~kg}$ ) than that of our obese children (body weight $67 \pm 4 \mathrm{~kg}$ ) which may explain why their subjects had a more subtle insulin resistance. Second, the control group used in their study also included adolescents who are known to normally be insulin-resistant and hyperinsulinaemic $[10,11]$. L astly, a greater secretion of gut factors or incretins in response to the ingestion of the meal in the obese subjects studied by the French authors may account for the greater insulin response compared to nonobese subjects. N evertheless, in order to assess these issues, longitudinal studies in subjects genetically predisposed to obesity should be carried out before the onset of the obese state. H owever, because obesity is a disease with extremely variable age of expression, these studies are difficult, if not impossible, to perform.

By using both a relatively low and high insulin dose in conjunction with $1^{13} \mathrm{C}$-glucose and indirect calorimetry, we were able to identify the target tissues involved and the intracellular defects responsible for the altered glucose metabolism in obesity of each stage of development. The results demonstrate that in preadolescent obese subjects insulin action is markedly impaired. This impairment in insulin-stimulated glucose metabolism was similar to that of the adolescent and obese adults, involving both pathways of oxidative and non-oxidative glucose metabolism. Similar defects have been reported in long-lasting obese states [31].

The defects in insulin action were not confined only to glucose metabolism but extended also to lipid metabolism. Similar findings were recently found by M onti et al. [32] in obese children. I nsulin's suppressive effect on plasma NE FA levels was found to be reduced in obese adolescents and adults vs control subjects during both the low and high insulin dose. Insulin infusion failed to suppress fat oxidation rates in all three groups of obese subjects. The obesity-induced defects in glucose and NEFA metabolism and fat oxidation, are likely to be closely related. $R$ andle et al. [33] were the first to propose that elevated levels of plasma NEFA may inhibit peripheral glucose metabolism. It is particularly noteworthy that recent studies have suggested that increases in NEFA levels induce defects in the non-oxidative as well as oxidative pathways of intracellular glucose disposal [34, 35]. Thus, it is conceivable that the defects in non-oxidative and oxidative glucose metabolism that were 
observed in our young obese subjects could be accounted for by the failure of insulin to suppress the rate of lipid oxidation.

In the present study we have found in both obese and non-obese preadolescents similar plasma NEFA concentrations in the basal state and during the clamp study. This may suggest that adipose tissue is not resistant to the action of insulin early in the development of obesity. In contrast to the fall in plasma in NE FA levels, we have found impaired suppression of lipid oxidation. We have measured net total lipid oxidation (extracellular + intracellular) with the use of indirect calorimetry. In the basal state, plasma NEFA accounts for $40-50 \%$ of net lipid oxidation, the remaining 50 $60 \%$ is derived from oxidation of intracellular lipids which are not in equilibrium with the plasma NEFA pool. Plasma NEFA oxidation and total lipid oxidation are differently regulated by insulin. I nhibition of plasma NEFA oxidation is more sensitive to insulin than total lipid oxidation rate [36]. Therefore, we speculate that the elevated rates of net lipid oxidation rates observed in the obese preadolescents are due to the impaired effects of insulin on oxidation of intracellular (muscle) lipid deposits which may contribute more to net lipid oxidation. O $n$ the other hand, insulin's effect on plasma NEFA oxidation may be preserved. Clearly, isotope infusion studies are needed to understand insulin's effects on NEFA turnover and disposal (oxidation and re-esterification) during the natural evolution of obesity.

In adults, insulin resistance and obesity are known to be important risk factors for the development of non-insulin-dependent diabetes [37]. Furthermore, hyperinsulinaemia has been found to be closely related to the metabolic and cardiovascular syndrome characterized by hypertension, dislipidaemia, central obesity, non-insulin-dependent diabetes and insulin resistance. We found that the metabolic profile characterized by insulin resistance, involving both glucose and fat metabolism, and hyperinsulinaemia is fully established before the onset of puberty in preadolescent children with moderate to severe obesity. N ew therapeutic strategies aimed at controlling weight gain or at reversing the metabolic consequences of obesity need to be developed and started early in the course of obesity in order to decrease the risks of the complications associated with this disorder.

A cknowledgements. We thank the nursing staff of the Pediatric $\mathrm{G}$ eneral Clinical R esearch Center for the excellent care given to our subjects during these studies. We are indebted to the staff of the Core Laboratory of the Clinical R esearch Center for their technical assistance and particularly thank Dr. G. Shulman for the measurements of $1-{ }^{13} \mathrm{C}$-glucose. We are grateful to M s. N. Canetti for the superb preparation of the manuscript.

Supported by grants from the $\mathrm{N}$ ational Institutes of $\mathrm{H}$ ealth (H D 28016, RR 00125, M O 1-R R 06022, D K 20495, H D 30671, DK 40936, DK 45735)

\section{References}

1. O lefsky J M, Kolterman O G, Scarlett JA (1982) Insulin action and resistance in obesity and non-insulin-dependent type II diabetes mellitus. A m J Physiol 243:E 15-E 30

2. L illoja S, B ogardus C (1988) O besity and insulin resistance: lessons learned from the Pima Indians. D iabetes M etab R ev 4: 517-540

3. Terrettaz J, A ssimacopoulos-Jeannet $F$, Jeanrenaud B (1986) Severe hepatic and peripheral insulin resistance as evidenced by euglycemic clamps in genetically obese fa/fa rats. E ndocrinology 118: 674-678

4. B eard J C, Ward WK, Halter J B, Wallum BJ, Porte D J r (1987) R elationship of islet function to insulin action in human obesity. J Clin Endocrinol M etab 65: 59-64

5. B agdade J D, Porte D, B runzell J D, B ierman E L (1974) B asal and stimulated hyperinsulinism: reversible metabolic sequelae of obesity. J L ab Clin M ed 83: 563-569

6. Cusin I, R ohner-J eanrenaud F, Terrettaz J, Jeanrenaud B (1992) H yperinsulinaemia and its impact on obesity and insulin resistance. Int J $O$ bes 16:S1-S11

7. K ruzynska Y T, Home PD, A lberti K GM M (1987) Insulin insensitivity and skeletal muscle enzyme activities in response to overinsulinization in the rat. Metabolism 36: 281-285

8. D el Prato S, L eonetti F, Simonson D, Sheehan P, M atsuda M, DeFronzo RA (1994) Effect of sustained physiologic hyperinsulinaemia and hyperglycaemia on insulin secretion and insulin sensitivity in man. D iabetologia 37: 1025-1035

9. L eStunff $C$, B ougnères $P$ (1994) E arly changes in postprandial insulin secretion, not insulin sensitivity, characterize juvenile obesity. D iabetes 43: 696-702

10. A miel SA, Sherwin RS, Simonson DC, Lauritano A A, Tamborlane WV (1986) Impaired insulin action in puberty: a contributing factor to poor glycemic control in adolescents with diabetes. N Engl J M ed 315: 215-219

11. Caprio S, Plewe G, D iamond M P et al. (1989) Increased insulin secretion in puberty: a compensatory response to reductions in insulin sensitivity. J Pediatr 114: 963-967

12. Travers S, Jeffers BN, Black C, Hill J O, Eckel R (1995) $G$ ender and Tanner stage differences in body composition and insulin sensitivity in early pubertal children. J Clin E ndocrinol M etab 80: 172-178

13. $\mathrm{H}$ ammer LD, K raemer HC, Wilson D M, R itter PL, D ornbusch SM (1991) Standardized percentile curves of body mass index for children and adolescents. A J D C 145: 259263

14. Caprio S, H yman D L , L imb C et al. (1995) Central adiposity and its metabolic correlates in obese adolescent girls. A m J Physiol (E ndocrinol M etab 32) 269:E 118-E 126

15. Finegood D T, B ergmamn R, V ranic M (1987) E stimation of endogenous glucose production during hyperinsulinemic, euglycemic glucose clamp: comparisons of unlabeled and labeled exogenous glucose infusate. D iabetes 36: 914-924

16. D eFronzo R A, Tobin J D, A ndres R (1979) G lucose clamp technique: a method for quantifying insulin secretin and resistance. A m J Physiol 237:E 214-E 223

17. Novak M (1965) Colorimetric ultramicro method for the determination of free fatty acids. J Lipid R es 6: 431-433

18. H awk PB (1947) K jeldahl method. In: Practical physiological chemistry. Blakison, Toronto pp 814-822

19. Wolfe R R (1992) R adioactive and stable isotope tracers in biomedicine. A lan R. L iss, Inc., N ew Y ork, pp 293-317

20. Caprio S, Gelfand RA, Tamborlane WV, Sherwin RS (1989) Oxidative fuel metabolism during mild hypoglycemia: critical role of free fatty acids. A m J Physiol 56:E 413E 419 
21. A miel S, Caprio S, Sherwin R S, Plewe G, Haymond M, Tamborlane WV (1995) Insulin resistance of puberty: a defect restricted to peripheral glucose metabolism. J Clin E ndocrinol M etab 72: 277-282

22. Pénicaud L, R ohner-J eanrenaud $F$, J eanrenaud $B$ (1986) In vivo metabolic changes as studied longitudinally after ventromedial hypothalamic lesions. A m J Physiol 250:E 662E 668

23. L eM archand $Y$, Freychet $P$, Jeanrenaud $B$ (1985) L ongitudinal study on the establishment of insulin resistance in hypothalamic obese mice. E ndocrinology 102: 74-85

24. Pénicaud L, Ferré P, Terrettaz J et al. (1987) D evelopment of obesity in Zucker rats: early insulin resistance in muscles but normal sensitivity in white adipose tissue. D iabetes 36 : 626-631

25. R izza R A, M andarino LJ, G enest J, B aker B A, G erich J E (1985) Production of insulin resistance by hyperinsulinaemia in man. Diabetologia 28: 70-75

26. M CG uinnes D P, M yers SR , N eal D, Cherrington A D (1990) Chronic hyperinsulinaemia decreased insulin action but not insulin sensitivity. M etabolism 39: 931-937

27. Marban SL (1992) H yperinsulinaemia precedes insulin resistance in a transgenic mouse model of type II diabetes. D iabetes 41[Suppl]:145A (A bstract)

28. M cG arry JD (1992) What if M inkowski had been ageusic? A $n$ alternative angle on diabetes. Science 258: 766-770

29. A bbott N, Foley JE (1987) Comparison of body composition, polypocyte size, and glucose and insulin concentrations in Pima Indians and Caucasian children. M etab Clin Exp 36: $568-576$

30. O deleye $O$, deC oveten $M, R$ avussin $E$ (1995) Insulin resistance as a predictor of body weight gain in 5-10 year old Pima I ndians. D iabetes 44 [Suppl 1]:7a-20

31. B onora E, D el Prato S, B onadonna R C et al. (1992) B ody fat content and fat topography are associated differently with in vivo glucose metabolism in nonobese and obese nondiabetic women. D iabetes 41: 1151-1159

32. M onti LD, Brambilla P, Stefani I et al. (1995) Insulin regulation of glucose turnover and lipid levels in obese children with fasting normoinsulinemia. D iabetologia 38: 739-747

33. $R$ andle PJ, G arland PB, N ewsholme E A , H ales CM (1965) The glucose fatty acid cycle in obesity and maturity onset diabetes mellitus. A nn NY A cad Sci 131: 324-333

34. K elley D E, M okan M, Simoneau JA, Mandarino LJ (1993) Interaction between glucose and fatty acid metabolism in human skeletal muscle. J Clin Invest 92: 91-98

35. Boden G, Chen X, Ruiz J, White JV, R ossetti L (1994) $M$ echanisms of fatty acid-induced inhibition of glucose uptake. J Clin Invest 93: 2438-2446

36. Groop L, Bonadonna RC, Shank M, Petrides A S, DeFronzo R A (1991) R ole of free fatty acid and insulin in determining free fatty acid and lipid oxidation in man. J Clin Invest 87: 83-89

37. DeFronzo R A, Bonadonna R, Ferrannini E (1992) Pathogenesis of NIDDM, a balanced overview. Diabetes Care 15: $318-368$ 